University of Nebraska - Lincoln

DigitalCommons@University of Nebraska - Lincoln

Hendricks Symposium--Department of Political

Science

Political Science, Department of

October 2006

\title{
Judgments about cooperators and freeriders on a Shuar work team: An evolutionary psychological perspective
}

Michael E. Price

Washington University

Follow this and additional works at: https://digitalcommons.unl.edu/politicalsciencehendricks

Part of the Political Science Commons

Price, Michael E., "Judgments about cooperators and freeriders on a Shuar work team: An evolutionary psychological perspective" (2006). Hendricks Symposium--Department of Political Science. 13.

https://digitalcommons.unl.edu/politicalsciencehendricks/13

This Article is brought to you for free and open access by the Political Science, Department of at DigitalCommons@University of Nebraska - Lincoln. It has been accepted for inclusion in Hendricks Symposium-Department of Political Science by an authorized administrator of DigitalCommons@University of Nebraska - Lincoln. 


\title{
Judgments about cooperators and freeriders on a Shuar work team: An evolutionary psychological perspective is
}

\author{
Michael E. Price* \\ Olin School of Business, Campus Box 1133, Washington University in St. Louis, 1 Brookings Drive, St. Louis, MO 63130-4899, USA
}

Received 21 November 2004

Available online 14 August 2006

\begin{abstract}
Evolutionary biological theories of group cooperation predict that (1) group members will tend to judge cooperative co-members favorably, and freeriding co-members negatively and (2) members who themselves cooperate more frequently will be especially likely to make these social judgments. An experiment tested these predictions among Shuar hunter-horticulturalists. Subjects viewed depictions of pairs of workers who varied in the extent to which they had contributed to, and benefited from, a team project. Subjects were then asked to judge which worker deserved more respect, and which deserved more punishment. When judging between unequalcontributors, all subjects tended to favor more cooperative (i.e., higher-contributing) workers. However, when judging between equal-contributors/unequal-benefiters, male subjects who themselves often engaged in team cooperation tended to favor more cooperative (i.e., lower-benefiting) workers, while subjects who were female and who therefore rarely engaged in team cooperation tended to favor less cooperative (i.e., higher-benefiting) workers.
\end{abstract}

(c) 2006 Elsevier Inc. All rights reserved.

Keywords: Cooperation; Work team; Collective action; Free rider; Punishment; Evolutionary psychology; Respect

\section{Introduction}

The freerider problem, social judgment, and human nature

In a collective action, individuals cooperate to produce some resource that they will share among themselves. Collective actions are common in human social

\footnotetext{
is The assistance of our Shuar hosts is deeply appreciated. Thanks also to Clark Barrett, Bill Bottom, Leda Cosmides, Kurt Dirks, Kevin Haley, Margaret Neale, Lin Ostrom, Jade Price, Ray Sparrowe, John Tooby, three anonymous reviewers, and participants in the lab group at the UCSB Center for Evolutionary Psychology, and in the evolutionary theory group at the Indiana University Workshop in Political Theory and Policy Analysis (WPTPA). This research was funded by the WPTPA, by a grant to the Santa Fe Institute from the James S. McDonnell Foundation-21st Century Collaborative Award Studying Complex Systems, and by a Jacob Javits Fellowship from the US Department of Education.

" Present address: School of Social Sciences \& Law, Brunel University, Uxbridge, Middlesex UB8 3PH, United Kingdom. Fax: +44 (0) 1895203018.

E-mail address: michael.price@brunel.ac.uk.
}

life (Ostrom, 1990), including in organizational contexts (Albanese \& Van Fleet, 1985; Goren, Kurzban, \& Rapoport, 2003): for example, members of a work team who jointly design some new product, and whose efforts bring rewards to all team members. However, collective actions must overcome some challenges in order to succeed, and chief among these is the freerider problem (Olson, 1965). If each member receives an equal share of the benefit that the group produces, no matter how much that member contributed to the production effort, then each member has a private incentive to contribute less than co-members. This incentive to freeride exists because if all members benefit equally, then the members who contributed the least to production will reap the highest net benefits. More formally: in a group of $n$ members, one's cost of contributing $c$ creates a public good, with a total benefit $m c$ that is shared equally by all members. One can contribute productively when $1<m$; however, if $1<m<n$, then one 
can profit more individually if one fails to contribute, and instead freerides on the contribution efforts of comembers.

So other things being equal, it would often seem rational for a collective action participant to not contribute at all, and to let co-participants do all the work. But if all participants adopt this strategy, then nobody in the collective action will cooperate, and the collective action will therefore fail. How are humans able to overcome this dilemma? Research suggests that people often solve freerider problems by directing social benefits towards cooperators, and/or by imposing social costs on freeriders (Andreoni, Harbaugh, \& Vesterlund, 2003; Fehr \& Gächter, 2000; Hawkes, 1993; Patton, 2000; Price, 2003, 2006; Price, Cosmides, \& Tooby, 2002; Yamagishi, 1986). This distribution of social benefits and costs occurs because observers make positive and negative social judgments about the behavior of cooperators and freeriders, respectively: cooperators are seen as virtuous and worthy of respect, reward, or some other form of social benefit, while freeriders are seen as irresponsible and deserving of condemnation, punishment, or some other form of social cost. These benefits and costs can be allocated either formally or informally (Falk, Fehr, \& Fischbacher, 2005; Price, 2006): for example, a cooperative team member may be rewarded formally with a salary increase, or informally with co-member respect; or, a freeriding member might be punished formally by being fired, or informally by losing respect.

While this pattern of judging cooperators positively and freeriders negatively has been well-documented in industrialized societies, evidence for its cultural universality, especially from small-scale societies, is lacking. If this pattern is universal, then it may reflect something deeper than just the norms or preferences of any particular culture, and could emanate from the ways in which Homo sapiens is psychologically adapted for cooperation in groups. It is reasonable to suggest that the human mind is adapted for such cooperation, because ancestral humans could have gained access to crucial fitness-enhancing resources by participating in successful collective actions in the evolutionary past (Chagnon, 1997; Hawkes, 1993; Price et al., 2002), for example in the contexts of group hunting and foraging, warfare, intergroup trade and alliancebuilding activities, predator defense, and shelter-building. Moreover, as will be explained below, the social judgments that people make in collective action contexts, at least in industrialized societies, are of a form that suggests that they are the products of psychological mechanisms that were shaped by natural selection.

Some evidence about social judgment patterns in small-scale societies does exist, and does tend to support the view that those observed in industrialized societies are indeed universal (Erasmus, 1977; Ostrom, 1990; Price, 2006). However, these accounts are largely anecdotal, and there is a need for additional, quantitative evidence. The study presented in this paper was primarily an effort to produce such evidence, by demonstrating that in a hunter-horticultural society in the Ecuadorian Amazon, villagers make negative judgments about freeriders and positive judgments about cooperators, just as they do in industrialized societies.

\section{The evolution of social judgment in collective actions}

An evolutionary biological perspective on cooperation suggests several categories of reasons why humans should make negative judgments about freeriders, and positive judgments about cooperators. Each category will be discussed in turn.

\section{Access to resources}

Participation in cooperative interactions such as collective actions would have been fitness-enhancing for ancestral humans, because it would have permitted them to access resources that they could not have acquired by acting alone (Alexander, 1979). The more cooperative and productive one's co-participants were in an ancestral collective action, the more one could have consumed the resources that they produced, and the better it would have been for one's fitness. Thus, a simple reason why ancestral humans should have evolved to prefer cooperators over freeriders is because this preference would have improved their access to resources. From this perspective, interactants in general (be they cooperators, freeriders, or some other type) should prefer cooperators as partners, because all types of interactants should benefit from having more productive co-interactants. Experimental evidence does suggest that both cooperators and freeriders prefer to interact with cooperators (Ehrhart \& Keser, 1999; Page, Putterman, \& Unel, 2005).

\section{Exploitation avoidance}

In order for cooperation to evolve, the benefits of cooperation must be preferentially directed towards cooperators, rather than towards freeriders. If cooperators can thus harvest the benefits of their labor preferentially for themselves, then they can prevent freeriders from gaining a fitness advantage. And as long as freeriders are not gaining this advantage, then cooperators can avoid being exploited and outcompeted by freeriders, and collective action can therefore evolve. There are two main ways in which this exploitation avoidance can occur. First, it can occur via positive assortment, if cooperators assort into cooperative interactions with other cooperators. 
Among non-kin ${ }^{1}$, positive assortment among cooperators may result if cooperators recognize, and interact preferentially with, other cooperators by virtue of some observable, difficult-to-fake phenotypic trait ("greenbeard") displayed by all cooperators (Dawkins, 1976; Hamilton, 1964). An obvious candidate for such a trait would be engagement in cooperative behavior itself (Dawkins, 1976; Price, 2006). Second, exploitation avoidance can occur via reciprocal altruism, if interactants cooperate only to the extent that they observe cointeractants to cooperate (Trivers, 1971). For example, A acts cooperatively towards B at first, and then continues to cooperate only as long $B$ reciprocates this cooperativeness; if $\mathrm{B}$ fails to reciprocate, $\mathrm{A}$ terminates the interaction, but if $\mathrm{B}$ reciprocates, then $\mathrm{A}$ and $\mathrm{B}$ proceed to engage in a mutually beneficial exchange relationship, for as long as both continue to reciprocate (Axelrod \& Hamilton, 1981).

Positive assortment and reciprocal altruism need not be mutually exclusive, and can in fact interact synergistically to promote the evolution of collective action, if reciprocators assort positively with other reciprocators (Boyd \& Richerson, 1988). Cross-cultural evidence from real-life and experimental collective actions confirms the predictions of both positive assortment and reciprocal altruism, which implies that both processes were important in enabling collective action to evolve (Page et al., 2005; Price, 2006; Tooby, Cosmides, \& Price, 2006). From the perspectives of positive assortment and reciprocal altruism, only cooperators (and not freeriders) are expected to interact preferentially with cooperators, because only cooperators face the problem of avoiding exploitation by freeriders.

\section{Partner motivation}

Because collective action participants benefit from having productive co-participants, they may make negative and positive social judgments, and engage in associated behaviors such as punishment and reward, in order to motivate increased partner contributions (Boyd, Gintis, Bowles, \& Richerson, 2003; Price et al., 2002). Experimental economic data suggest that monetary punishment alone is effective in promoting cooperation (Fehr \& Gächter, 2000; Ostrom, Walker, \& Gardner, 1992; Yamagishi, 1986), and that a combination of monetary punishment and reward is especially effective (Andreoni et al., 2003; Sefton, Shupp, \&Walker, under review); further, informal reward in the form of social

\footnotetext{
${ }^{1}$ In many species, positive assortment results from individuals interacting preferentially with their close genetic kin, because close kin are relatively likely to carry the same gene(s) for cooperation. This process of "kin selection" is the reason why in many species, cooperation is much more common among close kin than among non-kin (Hamilton, 1964). However, cross-culturally, collective actions often involve participants who are not close kin, so kin selection does not provide an adequate explanation for the evolution of collective action.
}

status appears to elicit cooperation in 'real life' interactions (Chagnon, 1988; Price, 2003, 2006). From the perspective of partner motivation, negative judgments of freeriders should be made mainly by cooperators, because freeriders should want to avoid advocating their own punishment; data do suggest that cooperators are more likely to judge freeriders negatively (Fehr \& Gächter, 2002; Price, 2005; Price et al., 2002; Shinada, Yamagishi, \& Ohmura, 2004). However, freeriders and cooperators should both advocate the reward of cooperators, since both can improve their access to resources by having productive co-interactants; consistent with this expectation, survey data suggest that the extent of one's self-interest in group production is positively correlated with the extent of one's support of contributor reward (Price et al., 2002).

\section{Reduction of freerider advantage}

Negative judgments and punishments directed at freeriders might be efforts not to coerce them into contributing, but rather to harm them, and thereby reduce their advantage (Price et al., 2002; see also Fehr \& Schmidt, 1999). From this perspective, negative judgments of freeriders should be made mainly by cooperators, because it is cooperators who will be disadvantaged relative to freeriders. As noted above, evidence does suggest that people who cooperate more are more punitive towards freeriders.

In summary, evolutionary theory gives several reasons to expect that social judgments about cooperators and freeriders should be positive and negative, respectively. However, only two of the reasons listed above assume that freeriders and cooperators should both be likely to make these judgments. These reasons are that both cooperators and freeriders can access more resources (1) by preferring to interact with cooperators, and (2) if their co-interactants are motivated to cooperate via reward. Every other reason named above assumes that cooperators should be more likely than freeriders to make these judgments. These reasons are that (1) cooperators alone have an additional incentive (beyond resource access) to prefer to interact with cooperators, in that only they face the problem of avoiding exploitation; and, that cooperators should be relatively interested in using punishment in order to (2) coerce freeriders into contributing, and to (3) reduce the freerider advantage. Therefore, while cooperators and freeriders share some reasons for making the expected social judgments, cooperators have some additional reasons of their own for making these judgments.

\section{How are cooperators and freeriders identified?}

In order to make positive and negative social judgments about cooperators and freeriders, respectively, one must have some criteria for identifying cooperators and freeriders. In industrialized societies, there appear to 
be three basic aspects of such identification: the extent to which the individual (1) contributed in the interaction, (2) benefited from the interaction, and (3) acted intentionally.

\section{Contribution}

This criterion appears to be of primary importance, and is the best studied of the three. Many recent studies of psychological and behavioral reactions to cooperators and freeriders have involved experimental collective actions known as public good games. Subjects in these games are assigned to groups, typically consisting of four or more members, and are given an equal endowment of tokens, redeemable for real cash at the end of the experiment. Subjects then have the opportunity to contribute any amount of this money to a group account. The experimenter multiplies these contributions by some factor $>1$ in order to produce a public good, and then redistributes this good equally among all members. Subjects are given no information about co-members other than co-members' contribution amounts, and they are often given the opportunity to punish (and sometimes, reward) co-members. Thus, subjects are expected to judge co-member behavior exclusively on the basis of contribution level. These studies do suggest that lower contributors receive more negative judgment and punishment. Specifically, they suggest that $\mathrm{X}$ will more likely be punished, the more X's contribution deviates negatively from the group average contribution (Fehr \& Gächter, 2000; Masclet, Noussair, Tucker, \& Villeval, 2003), or from the contribution of the punishing individual (Falk et al., 2005; Masclet et al., 2003).

\section{Benefit}

In public good game studies, extent of benefit has received less attention than extent of contribution. However, it has been the focus of a series of highly influential experiments showing that people are significantly better at solving a logic problem (the Wason selection task), when the problem is expressed in terms of detecting a cheater on a social contract having the abstract form "if you take the benefit, then you must pay the cost" (Cosmides, 1989; Cosmides \& Tooby, 1989, 1992). These results suggest that cheater-detection is enabled by a psychological system that is functionally specialized for detecting cheaters who have taken the benefit without paying the cost. This interpretation has been supported in subsequent studies, that have, for example, replicated this finding in a small-scale society (Sugiyama, Tooby, \& Cosmides, 2002); reported a selective impairment of the cheater-detection ability in a brain-damaged subject (Stone, Cosmides, Tooby, Kroll, \& Knight, 2002); and demonstrated the neural domain-specificity of the cheater-detection system via fMRI (Fiddick, Spampinato, \& Grafman, 2005). Assessment of benefit thus appears to be an important aspect of how the mind is adapted for cheater-detection. This attention to benefit probably reflects the fact that in order to cheat or freeride, one must benefit from the interaction; and more generally, one's benefit-to-contribution ratio determines where one falls on the continuum from narrowly self-interested freerider (high ratio), to self-sacrificing, altruistic cooperator (low ratio).

\section{Intentionality}

Intent appears to be a third important aspect of assessing cooperativeness. Non-contribution in a cooperative interaction can be intentional (e.g., skipping work to lie by the pool) or accidental (e.g., missing work due to unavoidable injury). Cross-cultural evidence suggests that only intentional non-cooperation counts as cheating or freeriding (Bottom, Gibson, Daniels, \& Murnighan, 2002; Delton, 2005; Dufwenberg \& Kirchsteiger, 1999; Price, 2005, 2006; Rabin, 1993; Singer, Kiebel, Winston, Dolan, \& Frith, 2004). Consideration of intentionality would make sense if a goal of punishment were to coerce contributions from freeriders, because punishment effort would be wasted on those unable to contribute. It would also make sense if people strive to associate with cooperators and to avoid freeriders, because only intentional non-cooperation is evidence of a non-cooperative disposition. While intent does appear to be an important aspect of assessing cooperativeness, the present study focused more on how people use information about contribution and benefit in making this assessment. (However as discussed below, even before beginning the study, it was clear that members of the study population do consider intent when making social judgments).

\section{The Shuar}

The study presented below was conducted in two neighboring Shuar hunter-horticulturalist villages, one of about 300 residents and the other of about 80 , located in the Ecuadorian province of Morona Santiago. The Shuar belong to a linguistic population called the Jívaro, and are perhaps best-known for their tradition of shrinking the heads of their enemies (Harner, 1972). Along with other Jívaro groups, they are also wellknown for having one of the most violent societies on the anthropological record, with historic male death rates from homicide of about $50 \%$ (Patton, 2005). Due to the pacifying influence of missionaries and modern legal systems, the head-shrinking tradition had disappeared by the 1960s, and the level of violent conflict in general has been much reduced over the past several decades (Steel, 1999). However, residents of the study villages sometimes do employ violence as a means of dispute resolution, for example, at the time of the study, an elderly woman had recently been murdered with a machete, the victim of an ongoing feud between two within-village lineages. The villages lack any formalized institution for resolving disputes, and police forces of the larger 
Ecuadorian society are often reluctant to intervene in Shuar conflicts, unless the violence gets seriously out of hand. Village affairs are administered by a democratically-elected government consisting of a president, vicepresident, secretary and treasurer, and one's social standing is greatly influenced by the extent to which one is perceived to act in ways that benefit the village (Price, 2003). Many of the most respected residents are those who are perceived to have served the community well in one or more of these elected offices. These residents appear to benefit from being respected in various ways, for example, they are able to maintain positions of political power and social influence, and they tend to have more offspring, and healthier daughters (Hagen, Barrett, $\&$ Price, 2006).

Like most modern small-scale societies, the study villages are at a stage of cultural transition in which they retain many of their traditional practices, while at the same time embracing some newer ones from the larger industrialist society. Many traditional Shuar practices are typical of Amazonian hunter-horticulturalists in general. They rely heavily on their crops of plantains and sweet manioc for food, but they supplement this diet by hunting jungle game. They maintain a traditional division of labor by sex, which has men doing the hunting and the more demanding physical labor such as shelter construction, and has women focusing on cultivating and processing garden products, and on caring for children. The Shuar generally speak their native tongue (Shuar) with one another, and the level of genetic relatedness among village residents is high by western standards. In the village of 300 , for example, the majority of residents are closely related descendents of two brothers who helped found the village. Analyses of a genealogy of six generations ${ }^{2}$ of village residents, using Kindemcom (Chagnon \& Bryant, 1984) and Kinsanity (Hagen, 2003) software, revealed the average resident to be a genetic relative of $47 \%$ of the other 299 current residents, and to have an average coefficient of relatedness of 0.045 with all other residents (for reference, the coefficient of relatedness is 0.50 for full siblings, 0.125 for first cousins, and 0.031 for second cousins). Many more modern Shuar practices are also typical of transitional Amazonian small-scale societies: timber sales are an important source of cash, and cash cropping is of limited but increasing importance; villages have had contact with missionaries (in this case, Protestant) for several decades, and most residents under the age of 60 can speak some Spanish in addition to Shuar.

\section{Shuar mingas}

The Shuar regularly practice traditional collective actions known as mingas. A minga involves a work team

\footnotetext{
${ }^{2}$ Much of these genealogical data were collected by Clark Barrett.
}

that cooperates in order to accomplish some common goal, for example clearing a field with machetes, or building a house. Little has been published about the origin and history of mingas, but by all accounts, including those of older informants who are most knowledgeable about traditional Shuar culture, they are a fairly ancient practice, among both Shuar and surrounding Andean/ Amazonian groups (Aguirre, 1952). The physical labor in mingas is primarily a male activity, although there are occasional exceptions to this rule (e.g., see below discussion of the female association member). However, women do contribute by preparing and distributing the chicha that men consume during breaks in the minga. (Chicha is a traditional, mildly-alcoholic drink, usually made of fermented, masticated yucca. The opportunity to consume chicha is the highlight of minga participation for many men). Mingas are of three general types: (1) general mingas, in which "citizens" (socios) in a village are expected to participate; (2) family mingas, in which invited family members are expected to participate; and (3) association mingas, in which all members of a within-village association are expected to participate.

Family mingas are the most informal kind of the three; these occur relatively spontaneously, and involve close family members working to improve some aspect of their private property, for example, "cleaning" family gardens (i.e., using machetes to hack down thick, intrusive jungle weeds), or adding a room to a home. The Shuar will typically invite several close relatives such as siblings and first cousins to their family mingas, and invitations are usually accepted. Unlike in the case of general and association mingas, absences from family mingas are not formally punished. General mingas are more formal affairs, and are organized by the village president, for public-good-enhancing tasks such as "cleaning" public spaces or making repairs on school buildings. General mingas last an entire workday, and attendance is taken by the village secretary in order to keep a record of how much residents owe in fines for nonattendance. For each minga, members are marked as either "present" (presente), "unjustifiably absent" (falta) or "justifiably absent" (justificado). A falta occurs when an absent member is perceived as having been capable of attending, and it is punished with a monetary fine. A justificado occurs when the absence is perceived as having been due to some unavoidable, incapacitating sickness or injury, and it is not fined. Thus, an absence's excusability depends on whether it is considered to have been intentional, and as in industrialized societies, accidental non-cooperativeness is not considered freeriding (Price, 2006). The president is responsible for collecting fines for faltas: at village meetings held every few weeks, the president reads aloud the names of fined members, who are expected to then come forward to pay their debts. Paid fines are 
deposited into a village account, for public expenditures such as school supplies, public building materials, and so forth.

Associations that hold mingas are groups of villagers who are united in the pursuit of an economic goal that requires a long-term cooperative effort. These associations assemble informally, and membership is open to adult villagers who are willing to put in the significant work hours that membership requires. Only one association existed in the two study villages at the time of study, a group of 13 cañicultores (sugarcane cultivators) who would hold mingas once or twice weekly, usually to clean their fields of the dense, rapidly-growing weeds that constantly threatened their crop. The cañicultores' goal was to produce sugar that they could sell in regional towns, and each member stood to gain an equal share of whatever profits the association could make. The cañicultores association had a democratically-elected president and secretary, and, analogously to how mingas occurred at the village level, the president organized their mingas, while their secretary kept attendance records so that fines could be collected for perceived intentional absences. The cañicultores association had one female member, the wife of the association president. Although it was unusual for female Shuar to participate in the primary physical labor of mingas, this woman would help with this work for at least some portion of most mingas. However, she also carried out the more traditional female role of preparing and distributing chicha to the other cañicultores.

The home village of the majority of study subjects held about 10 general mingas annually, according to the village secretary's records. Men in this village also reported participating in an average of 8 family mingas annually. ${ }^{3}$ These are the only two kinds of mingas that most Shuar men participated in, so the typical Shuar man participated in no more than about 18 mingas a year, or 1.5 per month. However, the 13 members of the cañicultores association participated in many additional mingas. According to association records, the cañicultores held 60 mingas between July 2000 and December 2001, an average of 3.3 per month (this study was conducted in the summer of 2002). Thus, over this period, the cañicultores had many extra minga opportunities, in addition to the 1.5 monthly opportunities that they shared with typical men.

\section{The experiment}

The goal of the experiment was to test predictions derived from the evolutionary theoretical considerations discussed above, by measuring subjects' judgments about cooperators and freeriders in a hypothetical minga. Specifically, the experiment focused on whether subjects

\footnotetext{
${ }^{3}$ Data about family minga frequency were collected by field colleagues Clark Barrett and Kevin Haley, for the Cross Cultural Games Project (PIs: Joe Henrich and Jean Ensminger).
}

judged higher-contributing workers more positively, and higher-benefiting workers more negatively (when controlling for worker contribution level). The experiment also investigated whether subjects who cooperated more, that is, who participated in more mingas, were especially likely to make the expected social judgments.

Previous studies (Price, 2003, 2005, 2006) also examined Shuar social judgments, but the present study differs from this earlier work in several significant ways: it relies on experimental rather than real-world data; it examines whether the extent of a worker's benefit impacts the judgments that are made about that worker, and whether subjects who cooperate more are more likely to make the expected social judgments; and, it involves a significantly larger subject population, and one that includes many females. Other recent research on cooperation in smallscale societies has focused on behavior in experimental economic games (Henrich et al., 2001, 2004), and one might question why the below study did not use an experimental collective action such as a public good game. There were three main reasons. First, the study focused on social judgments themselves, while economic games tend to focus on the behavior that results from these judgments (e.g., the imposition of punishment). Second, a study goal was to measure judgments about workers who benefited unequally from a semi-public good, and no standard experimental game allows subjects to benefit unequally in this way. Third, the unusual features of public good games, such as their formality, subject anonymity, and their basic premise that a public good can be produced out of thin air at the whim of the experimenter, might have confused subjects. The Shuar are unfamiliar with experiments in general, and an effort was made to design one that included recognizable elements, such as the minga, so that their responses would be as natural and informative as possible. The minga scenario that was used, which involved a work team constructing a system of pipes for the delivery of running water to village homes, was chosen because of its realistic aspects. Several Shuar villages have held mingas for the construction of such pipe systems, and informants from the study villages suggested that subjects would consider this scenario to be plausible.

The following hypotheses, derived from the theory discussed above, were tested:

1. Subjects will tend to make "pro-cooperation" judgments; in other words:

1a. When judging between unequally-contributing workers, subjects will tend to judge higher contributors more favorably.

1b. When judging between equally-contributing but unequally-benefiting workers, subjects will tend to judge higher benefiters less favorably.

2. The more frequently a subject participates in mingas, the more that subject will tend to make these procooperation judgments. 


\section{Method}

\section{Subjects}

These were 93 were adult residents of, or visitors to, one of two Shuar villages located several miles apart. $56 \%$ were male, and ages ranged from 18 to 59 $(M=31.71$; age determination method is described below). An effort was made to collect data from all men and women over the age of 18 in these villages. Potential subjects were approached in public spaces (e.g., at the community soccer field) or in their homes. A large majority of villagers who were asked to participate in the experiment agreed to do so. Older subjects tended to be male, because older Shuar females tend to be less outgoing than their male counterparts, and were therefore less likely to be present in the public spaces where subject recruitment took place.

\section{Experimental design and procedures}

Subjects were read a vignette (reprinted in English in the Appendix A; subjects were read a Spanish translation) that described a village, located alongside a river, that held a minga to construct a pipe system for bringing running water from the river to village homes. However, there were only enough pipes to reach the one-half of homes in the village that were closer to the river. Subjects were shown a diagram depicting this scenario (Fig. 1), and were told that although this minga had required a full day's labor from all village men, some had worked more than others. Subjects were then shown cards depicting minga workers (Fig. 2), each of whom varied in how much he had worked in the minga, and how much he had benefited from the minga (i.e., whether he lived close to or far from the river). Degree of work was depicted by a circle that was either $3 / 4$ full and accompanied by the number 9 (indicating nine hours of work), or $1 / 4$ full and accompanied by the number 3

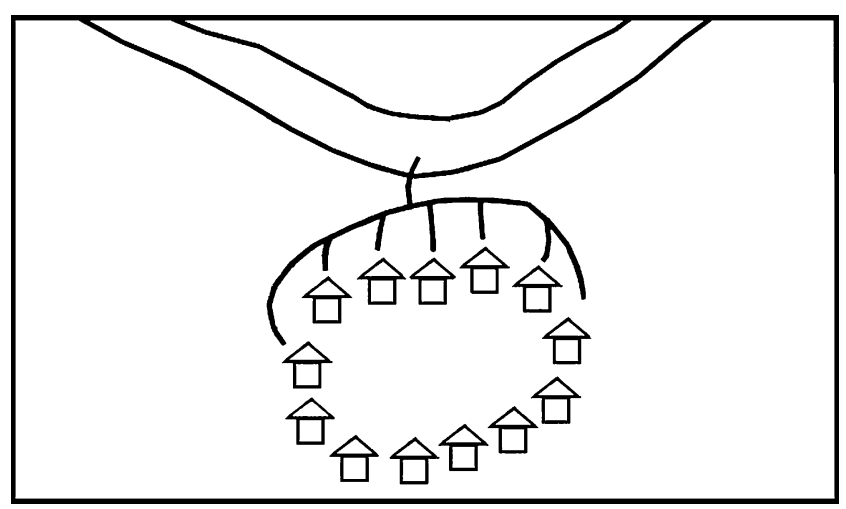

Fig. 1. Diagram of water system. Depicts the result of a minga for delivering running water from a river to village homes. There were only enough pipes to reach homes that were closer to the river, so the minga benefited only half of the villagers.
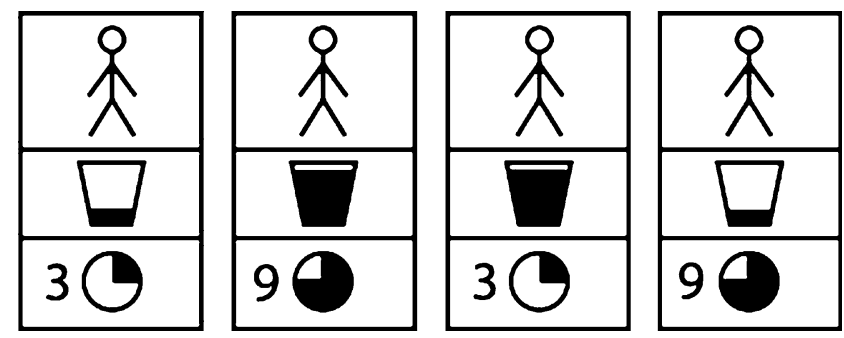

Fig. 2. Minga worker cards. Symbols represent degree of contribution to minga ( $3 / 4$ full circle and " 9 " = high contributor, $1 / 4$ full circle and " $3 "=$ low contributor), and degree of benefit from minga (full bucket $=$ high benefit, empty bucket $=$ low benefit). From left to right: Low benefit/low work, High benefit/high work, High benefit/low work ("Freerider"), Low benefit/high work ("Altruist").

(indicating three hours of work). Degree of benefit was depicted by a bucket of water that was either almost full (high benefit) or almost empty (low benefit). All possible combinations of degree of work and degree of benefit produced four worker types: (1) Low benefit/low work, (2) High benefit/high work, (3) High benefit/low work, and (4) Low benefit/high work. Note that High benefit/ low work would be considered a highly uncooperative freerider in industrialized societies, and Low benefit/high work a highly cooperative altruist; for clarity, these two workers will hereafter be referred to as Freerider and Altruist.

After the meanings of the symbols on the worker cards had been explained to subjects, subjects were asked to describe, to the experimenter, the meanings of the symbols on one or more different worker cards, until it became clear that these symbols were understood. The experiment then proceeded to the Respect Question Period. In this period, subjects were shown, in random consecutive order, each of the six possible paired combinations of the four workers: Low benefit/ low work versus Altruist, Freerider versus High benefit/high work, Low benefit/low work versus High benefit/high work, Freerider versus Altruist, Freerider versus Low benefit/low work, and High benefit/high work versus Altruist. As subjects were presented with each pair, they were asked (in Spanish), "Which one of these people deserves more respect, based on his participation in the minga?" After this question had been answered for all six pairs, the experiment continued to the Punish Question Period. Subjects were again shown all six pairs in random consecutive order, and were this time asked, "If you were the leader of this community, and you could decide whether community members should be punished based on their participation in the minga, which of these people would you think should be punished more?" To both of these questions, subjects could respond that they would respect/punish one worker more than the other, or that they could not decide (i.e. they would respect/punish neither, or respect/punish both equally). 
Table 1

Means, standard deviations, and Spearman correlations for Pro-cooperation, its component items, and Participation

\begin{tabular}{|c|c|c|c|c|c|c|c|c|c|c|c|c|c|c|c|}
\hline Variable & $M$ & s.d. & & 2 & 3 & 4 & 5 & 6 & 7 & 8 & 9 & 10 & 11 & 12 & 13 \\
\hline \multicolumn{16}{|l|}{ Respected more } \\
\hline $\begin{array}{l}\text { 1. Low benefit/low work } \\
\text { vs. Altruist }\end{array}$ & 0.95 & 0.20 & - & - & - & - & - & - & - & - & - & - & - & - & - \\
\hline $\begin{array}{l}\text { 2. Freerider vs. High benefit/ } \\
\text { high work }\end{array}$ & 0.92 & 0.27 & $0.35^{* *}$ & - & - & - & - & - & - & - & - & - & - & - & - \\
\hline $\begin{array}{l}\text { 3. Low benefit/low work vs. } \\
\text { High benefit/high work }\end{array}$ & 0.94 & 0.24 & $0.25^{*}$ & $0.36^{* *}$ & - & - & - & - & - & - & - & - & - & - & - \\
\hline 4. Freerider vs. Altruist & 0.88 & 0.33 & 0.02 & $0.58^{* *}$ & 0.14 & - & - & - & - & - & - & - & - & - & - \\
\hline $\begin{array}{l}\text { 5. Freerider vs. Low benefit/low } \\
\text { work }\end{array}$ & 0.40 & 0.42 & -0.03 & 0.16 & -0.06 & $0.30^{* *}$ & - & - & - & - & - & - & - & - & - \\
\hline $\begin{array}{l}\text { 6. High benefit/high work vs. } \\
\text { Altruist }\end{array}$ & 0.38 & 0.41 & -0.15 & 0.06 & $-0.31^{* *}$ & $0.25^{*}$ & $0.65^{* *}$ & - & - & - & - & - & - & - & - \\
\hline \multicolumn{16}{|l|}{ Punished less } \\
\hline $\begin{array}{l}\text { 7. Low benefit/low work vs. } \\
\text { Altruist }\end{array}$ & 0.91 & 0.28 & 0.16 & $0.26^{*}$ & 0.18 & 0.18 & 0.12 & 0.16 & - & - & - & - & - & - & - \\
\hline $\begin{array}{l}\text { 8. Freerider vs. High benefit/ } \\
\text { high work }\end{array}$ & 0.94 & 0.23 & $0.24^{*}$ & 0.07 & 0.10 & -0.10 & -0.02 & 0.03 & $0.63^{* *}$ & - & - & - & - & - & - \\
\hline $\begin{array}{l}\text { 9. Low benefit/low work vs. } \\
\text { High benefit/high work }\end{array}$ & 0.85 & 0.32 & $0.28^{* *}$ & $0.26^{*}$ & 0.15 & 0.07 & 0.01 & -0.10 & $0.37^{* *}$ & $0.21^{*}$ & - & - & - & - & - \\
\hline 10. Freerider vs. Altruist & 0.85 & 0.35 & 0.10 & 0.20 & 0.12 & $0.47^{* *}$ & $0.23^{*}$ & $0.21^{*}$ & $0.34^{* *}$ & 0.14 & 0.11 & - & - & - & - \\
\hline $\begin{array}{l}\text { 11. Freerider vs. Low benefit/low } \\
\text { work }\end{array}$ & 0.55 & 0.41 & 0.05 & 0.18 & -0.01 & $0.25^{*}$ & $0.49^{* *}$ & $0.40^{* *}$ & 0.17 & 0.04 & -0.07 & $0.46^{* *}$ & - & - & - \\
\hline $\begin{array}{l}\text { 12. High benefit/high work vs. } \\
\text { Altruist }\end{array}$ & 0.40 & 0.36 & -0.18 & 0.10 & -0.14 & 0.18 & $0.45^{* *}$ & $0.43^{* *}$ & 0.07 & 0.06 & -0.15 & $0.33^{* *}$ & $0.66^{* *}$ & - & - \\
\hline 13. Pro-cooperation & 8.96 & 2.00 & 0.17 & $0.44^{* *}$ & 0.12 & $0.49^{* *}$ & $0.73^{* *}$ & $0.63^{* *}$ & $0.44^{* *}$ & $0.29^{* *}$ & 0.19 & $0.57^{* *}$ & $0.71^{* *}$ & $0.65^{* *}$ & - \\
\hline 14. Participation & 1.68 & 0.68 & -0.04 & 0.14 & -0.08 & $0.25^{*}$ & $0.61^{* *}$ & $0.47^{* *}$ & 0.02 & 0.06 & -0.15 & 0.15 & $0.40^{* *}$ & $0.46^{* *}$ & $0.55^{* *}$ \\
\hline
\end{tabular}

Each of the six worker pairs presented to subjects was regarded as a separate variable, with values determined as follows: if the more cooperative worker in the pair (i.e., the higher contributor from a pair of unequalcontributors, or the lower benefiter from a pair of equal contributors) was judged more favorably (i.e., respected more or punished less), then the value was 1.0; if the less cooperative worker was favored, the value was 0.0 ; and if no decision was reached, the value was 0.5 . Because all six pairs were presented in both the Respect and Punish Question Periods, a total of twelve variables was created in this way. By summing these variables, a composite variable called Pro-cooperation was produced. Procooperation was designed to indicate the extent, on a scale of $0-12$, to which the subject favored the more cooperative worker, in all pairs presented across the entire experiment.

Three independent variables were measured. Two of these were Sex and Age. Age was determined by referencing each member's state-issued ID card or birth certificate. If these sources were unavailable, members' self-reported ages were recorded, then cross-checked by comparing them to ages of other individuals (e.g., siblings) whose ages were known, and interpolating based on birth order. The third independent variable, Participation, indicated how frequently the subject participated in mingas. As discussed above, subjects fell cleanly into three categories of participation frequency, and category assignments were determined as follows. Because men who belonged to the cañicultores association partici-

Table 2

Means, standard deviations, and Spearman correlations for pro-cooperation and predictor variables

\begin{tabular}{|c|c|c|c|c|c|c|c|c|}
\hline Variable & $M$ & s.d. & 1 & 2 & 3 & 4 & 5 & 6 \\
\hline 1. Pro-cooperation & 8.96 & 2.00 & - & - & - & - & - & - \\
\hline 2. Pro-cooperation-contribution & 7.23 & 1.29 & $0.60^{* *}$ & - & - & - & - & - \\
\hline 3. Pro-cooperation-benefit & 1.73 & 1.27 & $0.86^{* *}$ & 0.18 & - & - & - & - \\
\hline 4. Age & 31.71 & 9.82 & 0.20 & 0.11 & 0.16 & - & - & - \\
\hline 5. Sex & 1.56 & 0.50 & $0.47^{* *}$ & 0.07 & $0.56^{* *}$ & $0.22^{*}$ & - & - \\
\hline 6. Participation & 1.68 & 0.68 & $0.55^{* *}$ & 0.11 & $0.62^{* *}$ & $0.30^{* *}$ & $0.95^{* *}$ & - \\
\hline 7. Participation-males & 2.21 & 0.41 & $0.48^{* *}$ & 0.18 & $0.42^{* *}$ & $0.36^{* *}$ & - & - \\
\hline
\end{tabular}

$* p<.05$.

** $p<.01$. 
pated in many more mingas than typical men (4.8 versus 1.5 mingas per month), all available cañicultor subjects were classified as high participation $(N=11$; Participation value $=3$ ). Other male subjects were classified as medium participation $(N=41$; Participation value $=2)$, and, because mingas are almost exclusively a male activity, all female subjects were classified as low participation $(N=41$; Participation value $=1)$. The one female who participated often in mingas, the wife of the association president (described above), was considered unclassifiable because although she was a primary participant in many association mingas, she was not a primary participant in other kinds of mingas. As the only subject who did not fit cleanly into any of the three Participation categories, she was omitted from this study population. Her inclusion would not have had significant effects on the results presented below. ${ }^{4}$

\section{Results}

Variables $1-12$ in Table 1 represent worker pairs presented in the Respect Question Period (variables 1-6) and Punish Question Period (variables 7-12). (Subjects who said that a worker should be respected more were also more likely to say that that worker should be punished less). ${ }^{5}$ For these variables, a mean closer to 1.0 indicates that the more cooperative worker in that pair was more often favored. The composite variable Pro-cooperation was created by summing variables $1-12$, and indicates subjects' overall likelihood of favoring cooperators. Pro-cooperation was normally distributed

\footnotetext{
${ }^{4}$ How would the inclusion of this unclassifiable subject have affected the results? When judging between unequal-contributors, she, consistent with the large majority of all subjects, favored the higher-contributor in most ( 7 of 8 ) instances. When judging between equal-contributors, she favored the higher-benefiting (i.e., less cooperative) worker in 1 of 4 instances, and was unable to judge (tied) in 3 instances. Thus, when judging between equal-contributors, she did not display an unambiguously negative view of higher-cooperators (unlike many other female subjects), but nor did she display an unambiguously positive view of higher-cooperators (unlike many other cañicultores). Had her responses been included, they would not have altered any Table 1 mean or s.d. for variables $1-13$ by more than .01 , or any Table 1 correlation by more than .04, and no correlation would have gone from being significant to nonsignificant or vice-versa. Had she been classified as medium participation, her responses would not have altered any Table 2 mean or s.d. for variables $1-7$ by more than .01 , or any Table 2 correlation by more than .02, and no correlation would have gone from being significant to nonsignificant or vice-versa. Had she been classified as high participation, her responses would not have altered any Table 2 mean or s.d. for variables $1-7$ by more than .02 , or any Table 2 correlation by more than .05 , and no correlation would have gone from being significant to nonsignificant or vice-versa.

5 Judgments about a worker in the Respect Question Period (i.e., the sum of variables 1-6) were positively correlated with judgments about that worker in the Punish Question Period (i.e., the sum of variables 712) $\left(r_{s}=.58, p<.01\right)$. This correlation was not significantly affected by interaction effects with Sex or Age.
}

(K-S test, $p=.10$; all $p$ values are 2-tailed) and had moderately high internal consistency $(\alpha=0.75)$, and its mean of 8.96 (on a scale of 0 to 12) indicates that across the entire experiment, subjects were about $75 \%$ likely to favor the more cooperative worker.

However, subjects clearly favored cooperators only when judging between unequal-contributors, and not when judging between equal-contributors/unequalbenefiters. While the means of variables $1-4$ and 7-10 in Table 1 (which represent pairs of unequal-contributors) were all at least 0.85 , the means of variables 5-6 and 11-12 (which represent pairs of equal-contributors/ unequal-benefiters) were all in the range of 0.38-0.55. Fig. 3 illustrates that when judging between unequal contributors, most subjects favored the higher contributor, while few favored the lower contributor, and few were unable to decide. Fig. 4 shows that when judging between equal-contributors/unequal-benefiters, many subjects favored the higher benefiter, many favored the lower benefiter, and many were unable to decide.

Did Age, Sex or Participation explain any variance in social judgments? Table 2 suggests positive relationships between Pro-cooperation and Age $\left(r_{s}=.20\right.$,

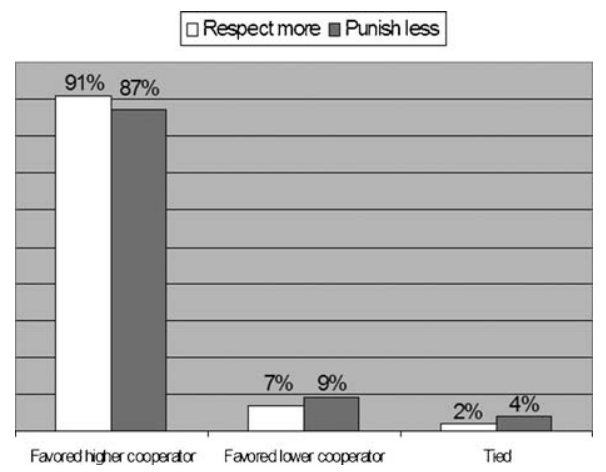

Fig. 3. Unequal contribution, equal or unequal benefit. When judging between two minga workers who had contributed unequally, a large majority of subjects favored the higher contributor. The extent to which a worker benefited had little impact on judgments.

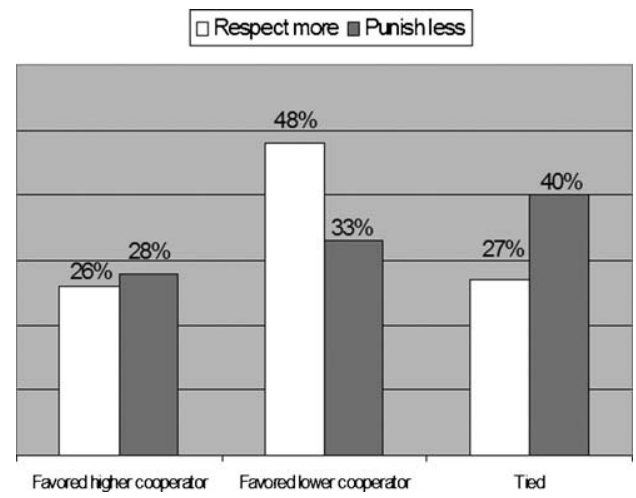

Fig. 4. Equal contribution, unequal benefit. When judging between two workers who had contributed equally and benefited unequally, the rationale for judgments was less clear than it had been for judgments of unequal-contributors, and subjects had more difficulty deciding. 
$p=.05), \operatorname{Sex}\left(r_{s}=.47, p<.01\right)$ and Participation $\left(r_{s}=.55\right.$, $p<.01)$. However, linear regression of Pro-cooperation on Sex, Age and Participation revealed that Participation alone explained significant unique variance in Procooperation (partial $r=.28, p<.01$ ). Age failed to explain unique variance (partial $r=.08, p=.46$ ) because it correlated with both of the other two predictor variables. Age correlated positively with $\operatorname{Sex}\left(r_{s}=.22\right.$, $p<.05)$ because older men were more likely than older women to be present during subject recruitment (discussed above). The correlation of Age with Participation $\left(r_{s}=.30, p<.01\right)$ reflects not only this Age-Sex correlation (because Participation score was heavily dependent on Sex), but also the fact that the mean age of cañicultores (40.27) was higher than that of non-cañicultores (30.56), and older subjects were therefore more likely to be coded as high-participation. For these reasons, the nearly-significant correlation between Age and Pro-cooperation seemed best explained as a by-product of the correlations between Age and the other two predictor variables, and therefore Age was omitted from further analysis. With Age omitted from the model, Participation continued to explain unique variance in Pro-cooperation (partial $r=.31, p<.01$ ), while Sex continued to explain none (partial $r=.09, p=.41$ ). Sex failed as a predictor here because it was so highly correlated with Participation $\left(r_{s}=.95, p<.01\right)$; as discussed above, all female subjects and no male subjects were classified as low-participation, because the primary labor of mingas is almost exclusively a male activity. The failure of Sex to explain unique variance in Procooperation indicated not that variance in Pro-cooperation was unrelated to sex differences, but rather that all of the predictive power of Sex was captured by the way in which Participation was coded. However, the fact that Participation explained variance in Pro-cooperation, beyond that explained by Sex, suggested that Participation had an important predictive component that Sex did not share (more on this topic below).
Although Participation explained variance in Procooperation, it was significantly positively correlated $(p<.05)$ with only one out of Pro-cooperation's eight component items which represented pairs of unequalcontributors, but was highly positively correlated $(p<.01)$ with each of Pro-cooperation's four component items which represented pairs of equal-contributors/ unequal-benefiters. To further investigate this asymmetry, Pro-cooperation was divided into two new composite variables: Pro-cooperation-contribution, which summed the values of the unequal contributor items $(\alpha=0.71)$, and Pro-cooperation-benefit, which summed the values of the equal contributor/unequal benefiter items $(\alpha=0.81)$. As Table 2 shows, Participation was significantly positively correlated with Pro-cooperationbenefit $\left(r_{s}=.62, p<.01\right)$, but not with Pro-cooperationcontribution $\left(r_{s}=.11, p=.29\right)$. Therefore, compared to lower-participation subjects, higher-participation subjects were more likely to favor workers who benefited less but contributed equally, but were not more likely to favor workers who contributed more (because all subjects, regardless of Participation category, overwhelmingly favored higher-contributors).

Because Participation was so dependent on sex, the high correlation between Participation and Pro-cooperation-benefit might actually have been more related to sex than to minga participation. In order to control for sex, low-participation subjects $(N=41$, all female) were omitted from the analysis, and only males $(N=52)$ were included, thus allowing for a direct comparison between medium- and high-participation males; the Participation variable used for this analysis will be referred to as Participation-males. Correlations between Participation-males and the three pro-cooperation measures were analyzed, and results (Table 2) were largely consistent with the analysis that had included females: Participation-males was positively correlated with Pro-cooperation $\left(r_{s}=.48\right.$, $p<.01)$ and Pro-cooperation-benefit $\left(r_{s}=.42, p<.01\right)$, but not with Pro-cooperation-contribution $\left(r_{s}=.18, p=.19\right)$.

Table 3

Judgments (by minga participation category) about Freerider versus low benefit/low work

\begin{tabular}{|c|c|c|c|c|c|c|}
\hline \multirow[t]{2}{*}{ Minga participation category } & \multicolumn{2}{|c|}{ Favored Freerider } & \multicolumn{2}{|c|}{ Favored low benefit/low work } & \multicolumn{2}{|c|}{ Tied (could not decide) } \\
\hline & Respected more & Punished less & Respected more & Punished less & Respect & Punish \\
\hline High & $1 / 11(9 \%)$ & $0 / 11(0 \%)$ & $10 / 11(91 \%)$ & $8 / 11(73 \%)$ & $0 / 11(0 \%)$ & $3 / 11(27 \%)$ \\
\hline Medium & $12 / 41(29 \%)$ & $9 / 41(22 \%)$ & $14 / 41(34 \%)$ & $20 / 41(49 \%)$ & $15 / 41(37 \%)$ & $12 / 41(29 \%)$ \\
\hline Low & $31 / 41(76 \%)$ & $17 / 41(42 \%)$ & $1 / 41(2 \%)$ & $8 / 41(20 \%)$ & $9 / 41(22 \%)$ & $16 / 41(39 \%)$ \\
\hline
\end{tabular}

Table 4

Judgments (by minga participation category) about Altruist versus high benefit/high work

\begin{tabular}{|c|c|c|c|c|c|c|}
\hline \multirow[t]{2}{*}{ Minga participation category } & \multicolumn{2}{|l|}{ Favored Altruist } & \multicolumn{2}{|c|}{ Favored high benefit/high work } & \multicolumn{2}{|c|}{ Tied (could not decide) } \\
\hline & Respected more & Punished less & Respected more & Punished less & Respect & Punish \\
\hline High & $8 / 11(73 \%)$ & $6 / 11(55 \%)$ & $3 / 11(27 \%)$ & $0 / 11(0 \%)$ & $0 / 11(0 \%)$ & $5 / 11(45 \%)$ \\
\hline Medium & $12 / 41(29 \%)$ & $8 / 41(20 \%)$ & $13 / 41(32 \%)$ & $11 / 41(27 \%)$ & $16 / 41(39 \%)$ & $22 / 41(54 \%)$ \\
\hline Low & $2 / 41(5 \%)$ & $2 / 41(5 \%)$ & $29 / 41(71 \%)$ & $23 / 41(56 \%)$ & $10 / 41(24 \%)$ & $16 / 41(39 \%)$ \\
\hline
\end{tabular}


These results suggested that the relationship between Participation and Pro-cooperation was not just a sex effect.

The correlation between Participation and Pro-cooperation-benefit existed not only because high-participation subjects tended to favor lower-benefiters, but also because low-participation subjects tended to favor higher-benefiters. Tables 3 and 4 display the judgments made by subjects in each of three minga participation categories, about the two pairs of equal-contributors/ unequal-benefiters. These tables show that high-participation subjects tended to disfavor Freerider and favor Altruist, low-participation (i.e., female) subjects tended to favor Freerider and disfavor Altruist, and mediumparticipation subjects fell between these two extremes. Differences among the three participation categories became still clearer when "tie" responses were omitted from the analysis (Figs. 5, 6).

Binomial tests on Fig. 5 data indicated that low-participators respected Freerider more than Low benefit/ low work $(p<.01)$, high-participators respected Low benefit/low work more than Freerider $(p<.05)$, and medium-participators respected neither worker more $(p=.85)$; further, high-participators punished Freerider

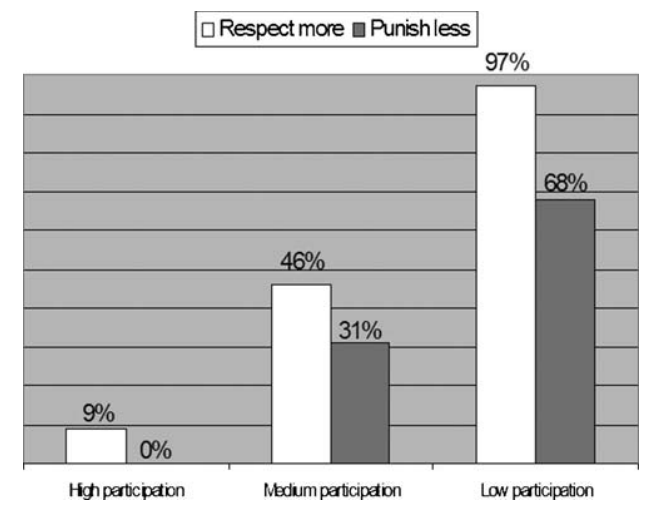

Fig. 5. Percent of subjects from each minga participation category who favored Freerider over Low benefit/low work (ties omitted). Lowerparticipation subjects judged Freerider more favorably.

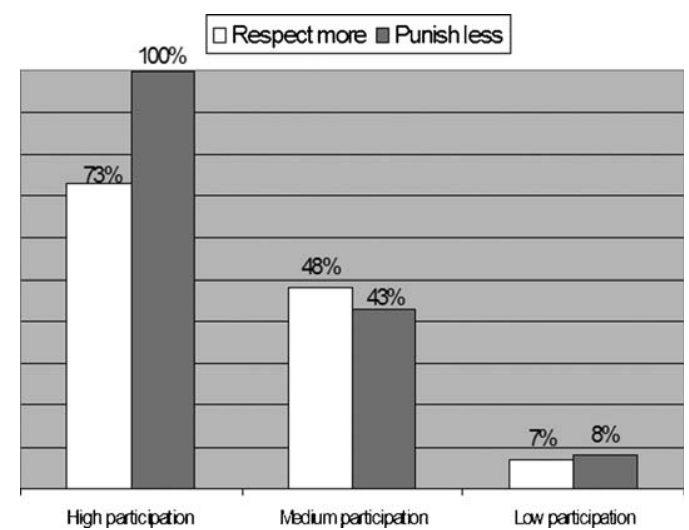

Fig. 6. Percent of subjects from each minga participation category who favored Altruist over High benefit/high work (ties omitted). Higherparticipation subjects judged Altruist more favorably. more than Low benefit/low work $(p<.01)$, medium-participators punished Freerider marginally more than Low benefit/low work $(p=.06)$, and low-participators punished Low benefit/low work marginally more than Freerider $(p=.11)$. Mann-Whitney $U$ tests on Fig. 5 data indicated that compared to low-participators, both highand medium-participators respected Freerider less $(p<.01)$, and that compared to medium-participators, high-participators respected Freerider marginally less $(p=.08)$; further, compared to low-participators, both high- and medium-participators punished Freerider more $(p<.01)$, but compared to medium-participators, high-participators did not punish Freerider more $(p=.25)$.

Binomial tests on Fig. 6 data indicated that low-participators respected Altruist less than High benefit/high work $(p<.01)$, while medium- and high-participators respected neither worker more ( $p=1.00$ and 0.23 , respectively); further, low-participators punished Altruist more than High benefit/high work and high-participators punished High benefit/high work more than Altruist $(p<.01$ and .05 , respectively), while medium-participators punished neither worker more $(p=.65)$. Mann-Whitney $U$ tests on Fig. 6 data indicated that compared to low-participators, both high- and medium-participators respected Altruist more $(p<.01)$, but compared to medium-participators, high-participators were not significantly more likely to respect Altruist $(p=.19)$; further, compared to low-participators, both high- and medium-participators punished Altruist less $(p<.01)$, and compared to medium-participators, high-participators punished Altruist less $(p<.05)$.

\section{Discussion}

Results of the study suggested three main ways in which Shuar judgments about worker behavior are shaped by information about a worker's degree of contribution to, and benefit from, a minga. First, when judging between unequally-contributing workers, all subjects - regardless of age, sex, or minga participation frequency - tended to judge the higher-contributor more positively. Second, when judging between equally-contributing unequally-benefiting workers, male subjects who more frequently participated in mingas were more likely to favor altruists and disfavor freeriders. Third, when judging between equally-contributing unequallybenefiting workers, subjects who were female and therefore infrequent minga participants, tended to favor freeriders while disfavoring altruists. Each of these three results will be discussed in turn.

First finding: All subjects tended to favor higher-contributors, when judging between unequal-contributors. When subjects judged worker behavior, information about the worker's contribution seemed more salient 
than information about the worker's benefit, and higher contributors were judged more positively, regardless of how much they benefited. This pattern of basing judgments on contribution level is highly consistent with the ways in which subjects make judgments in experimental collective actions (Fehr \& Gächter, 2000; Ostrom et al., 1992), and with existing qualitative accounts of attitudes towards cooperators and freeriders in small-scale societies (Ostrom, 1990). The tendency of subjects to favor higher contributors probably reflects the Shuar policy, noted above, that regards all adult villagers as being equally responsible for contributing to general mingas. This policy makes sense in light of the fact that these mingas are usually efforts to produce public goods that are considered to be accessible to all villagers. However, an unusual feature of the minga scenario used in this experiment was that it was explicitly portrayed as benefiting some villagers more directly than others. This manipulation was necessary in order to measure judgments about differences in degree of benefit, but it presented subjects with a somewhat novel problem: how to assess cooperativeness in a minga that explicitly benefits some residents more than others. Nevertheless, few subjects wavered from the policy that all residents should contribute equally; in effect, therefore, subjects often judged that workers should subsidize the well-being of their neighbors.

Why did subjects tend to look favorably on such neighbor subsidization? Part of the explanation might be the fact that, as noted above, Shuar villages contain large numbers of close genetic kin, and kin altruism (Hamilton, 1964) might raise expectations about the degree of within-village cooperation. However, kin altruism should be directed specifically at one's close kin, and not indiscriminately at one's village as a whole, so it is not a very precise explanation for the expectation of neighbor subsidization. An alternative explanation is that the Shuar assume that ultimately, over the course of repeated mingas, the distribution of minga benefits will even out among all villagers: if $\mathrm{X}$ works for X's neighbors this time, X's neighbors may work for X next time. Work effort in mingas may thus be a form of reciprocal altruism (Trivers, 1971), or of "greenbeard" reciprocity combining the effects of positive assortment and reciprocal altruism (Price, 2006). As long as the reciprocity system is not unfairly skewed such that mingas routinely benefit some villagers more than others, then villagers should be able to give in the confidence that they will later receive. In the scenario presented to subjects, extent of benefit depended on whether workers happened to live next to the river, and in Shuar villages, the extent to which a family's dwelling is located near a river does not in itself indicate anything in particular about the family's social status, degree of kin relatedness to village co-residents, or any other form of general social advantage. If subjects assumed that the minga's unequal benefit distribution was the result of an arbitrary factor (an insufficient supply of pipes), and did not assume that mingas in this village routinely advantaged one group over another, then they may have seen no reason for lesser-benefiting workers to withhold contributions: the benefits of random chance, unlike those of unfair design, should become equally distributed among all villagers over time.

Second finding: Subjects who participated in more mingas were more likely to favor altruists and disfavor freeriders, when judging between pairs of equally-contributing, unequally-benefiting workers. More-frequent minga participants were more likely to make pro-cooperation judgments, even after controlling for subject sex. However, this increased likelihood was evident only when subjects were evaluating pairs of equally-contributing, unequally-benefiting workers. The evolutionary theory presented above predicts that both cooperators and freeriders should favor cooperators, but that cooperators should be especially likely to do so, because cooperators should be relatively interested in avoiding exploitation by, and in being punitive towards, freeriders. This prediction was supported to some extent, although it is not immediately clear why the relationship between participation and pro-cooperativeness showed up only with regard to judgments about equally-contributing, unequally-benefiting workers. It may be that because assessment of cooperativeness is based primarily on information about contribution, the task of detecting freeriders and cooperators becomes more difficult when controlling for contribution. The cañicultores, as frequent team cooperators, may be primed to judge worker behavior in a more discriminating way, and be more sensitive to secondary cues of cooperativeness such as degree of benefit. In other words, some kind of environmental information, related to the experiences of belonging to the cañicultores association and/or of participating in their mingas, may activate a psychology of social judgment that makes the cañicultores more likely to base their judgments on teamwork-relevant criteria. In support of this view, evidence does suggest that information about one's social context can affect one's psychological disposition in cooperative tasks. For example, subjects who have been cued to adopt a position of high social rank seem relatively tolerant of freeriding by others (Fiddick \& Cummins, in press), and group members cooperate more when they perceive that the goal of this cooperation is to compete with an outgroup (Bornstein \& Ben-Yossef, 1994). However, it is also important to consider that the increased pro-cooperativeness of the cañicultores may in fact be a cause, rather than an effect, of frequent minga participation (see below).

Third finding: Subjects who were females and therefore infrequent minga participants tended to favor freeriders 
and disfavor altruists, when judging between equal-contributors/unequal-benefiters. Given the apparent relationship between pro-cooperativeness and minga participation, the tendency of Shuar females to make judgments that were the opposite of those of the cañicultores may be interpretable as follows. Shuar females rarely participate in mingas, which suggests that they should also be less likely to judge workers in terms of teamwork-relevant attributes. Therefore they may default to assessing workers in terms of their desirability as allies and/or mates, and focus on their ability to procure resources. Indeed, many female subjects were asked, after completing the experiment, why they had favored Freerider and disfavored Altruist, and all responded that it was because Freerider had more water, and Altruist had less. Apparently, Shuar women tended to regard Freerider as just a superior resource procurer (and perhaps as a relatively efficient one, who could acquire many resources without investing much time and effort), and Altruist as an inferior, and perhaps inefficient, resource procurer.

If female Shuar subjects were expressing a preference for males with more resources, then their responses would be highly consistent with cross-cultural data about female mate preferences. In the vast variety of cultures in which human mate preferences have been studied, females are consistently more likely than males to rank access to resources as an important mate attribute. As Buss and Schmidt (1993) point out, this universal asymmetry is consistent with the theory that in the evolutionary past, acquiring a resource-wealthy mate was relatively more important to female fitness than to male fitness. However, note that while a preference for resource-wealthy men might incline Shuar women to sometimes look negatively upon altruistic behavior in a minga, it does not suggest that these women look negatively upon cooperative resource-sharing in general; indeed, it suggests that they look favorably upon the possibility that a worker might share his resources with her.

Implications of these results for organizational behavior researchers. The most unambiguous result of the above study, and the one that is most clearly consistent with data about group cooperation in many industrialized societies (Fehr \& Gächter, 2000; Falk et al., 2005; Masclet et al., 2003; Yamagishi, 1986), is that when workers to a team project are judged based on contribution level, higher-contributors are judged more positively and lower-contributors are judged more negatively. The evolutionary theory discussed above presents plausible reasons to expect that Homo sapiens should be psychologically adapted to judge group members in these ways, and therefore that humans from all cultures, even cultures that are vastly different from one another in some respects, should display such judgments. The above study was conducted in a small-scale hunter- horticultural culture that is in fundamental respects quite different from industrialized cultures, so the similarity of Shuar judgments to those of members of industrialized societies provides some support for this evolutionary view. The Shuar of course represent only one non-industrialized culture, and more data are needed before any firm conclusions can be drawn about the psychological universality of such social judgments. However as noted above, qualitative studies conducted in small-scale societies have provided results that seem basically consistent with these Shuar data (Erasmus, 1977; Ostrom, 1990), and if further studies continue to support the universality of such judgments, then it would be useful for organizational behavior researchers to consider that when they are conducting research in any cultural context, regardless of the culture's level of industrial development, they can reasonably expect for group members to judge high- and low-contributing co-members positively and negatively, respectively.

The prediction that workers will be judged based on their benefit level has been relatively under-studied in industrialized societies, compared to the prediction that workers will be judged based on contribution level. Nevertheless, this prediction has received some confirmation in previous studies (Cosmides \& Tooby, 1992; Sugiyama et al., 2002), and received an additional amount of qualified support in the above study. If members of cooperative groups do tend to judge each other based on level of benefit from a group-produced resource, then knowledge about this effect would help organizational behavior researchers to understand the psychological and behavioral dynamics of many types of cooperative interactions that are common in industrialized societies, particularly interactions which produce semi-public goods. For example, in Western societies, all citizens of the same income level are sometimes expected to contribute equally to school bonds, even though these bonds should benefit parents of school-age children more directly than other citizens. The theory presented above would predict that in this situation, citizens who failed to contribute would be judged more negatively if they were parents of school-age children than if they were not.

The prediction that subjects who more frequently cooperate will be more likely to favor cooperators and disfavor freeriders has also been confirmed in previous studies (Fehr \& Gächter, 2002; Price, 2005; Price et al., 2002; Shinada et al., 2004), and received some support in the above study. If more cooperative members are relatively judgmental about the extent of cooperative behavior exhibited by co-members, then knowledge of this effect could be applied in useful ways. For example, one might attempt to improve morale on a work team by expelling 'negative' members who hold unfavorable opinions of co-members. However, the above study suggests that such a remedy could be disastrous: if the negative judgments are directed towards low cooperators, 
than negative members may also be the most cooperative members, and therefore the last members that one would want to expel.

Finally, with regard to the relationship between subject sex and judgments about equal-contributors/ unequal-benefiters, additional research is needed in order to determine whether this relationship is best explained in terms of sex differences, as opposed to differences in team participation or some other variable. Sex differences in social judgments was not a prediction of this study, and it is not clear whether female subjects' tendency to favor freeriders and disfavor altruists was related to their perception of workers as team cooperators, or as potential allies/mates. A female preference for resource-wealthy males would be consistent with the cross-cultural mate preference literature (Buss \& Schmidt, 1993), and there do appear to be some differences with regard to how males and females judge the behavior of cooperative partners. For example, compared to females, males appear both to experience more pleasure and less empathy when seeing non-cooperators punished (Singer et al., 2006), and also to punish non-cooperators more 'on principle', that is, with less concern for the economic impact that such punishment will have on themselves (Eckel \& Grossman, 1996). Differences with regard to how male and female team members evaluate the cooperativeness of co-members could have important implications for how organizational behavior researchers understand the psychology of team cooperation, but more research is needed to investigate such differences, and while the findings of the study presented above may be provocative, they are certainly not conclusive.

Limitations. Several limitations of the above study should be acknowledged. First, while the study suggested that more-frequent minga participants were more pro-altruist and anti-freerider, an important limitation on interpreting this finding was placed by the fact that all females, and no males, were low-participation, which resulted in sex and participation being highly confounded. This limitation was circumvented by omitting females from the sample, and then comparing medium- and high-participation males, an analysis which indicated that pro-altruist and antifreerider judgments were indeed related to participation, and not just to a sex effect. This result suggested that the correlation between being female, and the tendency to make pro-freerider and anti-altruist judgments, was to some extent due to the fact that females are low-participation; however, this result did not address the issue of whether this correlation could also have been bolstered by a sex effect. In order to resolve this question, a sample would be needed from a society in which females and males both routinely cooperated on work teams.
A second limitation was related to the assumption that it was minga participation itself that caused the cañicultores to regard cooperators relatively favorably. The variable of minga participation was measured somewhat crudely, with groups of subjects being classified as high-, medium-, or low-participation. While it was clear both that the cañicultores participated in more mingas than typical Shuar men, and also that typical Shuar men participated in more mingas than Shuar women, the variable of minga participation would ideally have been measured more precisely, on an individual-by-individual basis. Further, while it was assumed that inconsistencies in social judgments between cañicultores and other subjects were due to the cañicultores' increased minga participation, these inconsistencies may have been due to some other systematic difference between cañicultores and others. Age was considered above as one such difference, because the cañicultores tended to be older than other subjects, but was found to explain no unique variance in attitudes towards cooperators. Another intriguing possibility that was more difficult to address in this study was that the increased pro-cooperativeness of the cañicultores was actually a cause, rather than an effect, of frequent minga participation. Membership in the cañicultores could be an outcome of having pro-cooperation attitudes, if teamwork-oriented individuals were more likely to join the cañicultores. Future research will need to focus more closely on whether engagement in cooperation actually activates the expression of pro-cooperation judgments, or whether people who make these judgments are more likely to engage in cooperation.

A third limitation was related to the fact that only a single vignette, the river minga scenario, was used to assess judgments about cooperators and freeriders. While there is no reason to think that this type of scenario should be particularly likely to evoke biased subject responses, the use of more than one kind of vignette in the study would have decreased the likelihood of such bias, and so would have been preferable.

\section{Conclusion}

Overall, results of the study were largely consistent with the predictions that all subjects would tend to make pro-cooperation judgments, and that more-frequent minga participants would be especially likely to make these judgments. However, these results offered two unexpected twists. First, while degree of minga participation did correlate positively with pro-cooperativeness when comparing equal-contributors/unequal-benefiters, it did not do so with regard to comparisons of unequalcontributors: all subjects, regardless of participation level, were overwhelmingly likely to favor higher 
contributors in the latter type of comparisons. Second, low-participation subjects (females) tended to make anti-cooperation judgments when comparing equal-contributors/unequal-benefiters.

More cross-cultural testing is required before firm conclusions can be drawn about the extent to which the above results illuminate human cognitive adaptations for participation in collective actions for the production of public- or semi-public goods. The fact that there is much to learn about this topic is understandable, given that researchers are just beginning the systematic data collection that is needed in order to rigorously investigate the ways in which humans may be adapted for, and predisposed towards, cooperative behavior. This investigation will require efforts to illuminate the psychological substrate underlying human behavior in group actions cross-culturally, and the above study is intended as one such effort. The more we know about how humans are predisposed to cooperate, the more we can use this knowledge in order to promote cooperation in any kind of cultural context, by designing social and organizational institutions that utilize the potential of these cooperative predispositions.

\section{Appendix A. English translation of experimental scenario}

Imagine that a community is going to have a minga to build a system of pipes that will bring running water up to the houses of the people in the community. But, there are only enough pipes to bring water to half of the community. Only the houses that are closest to the river are within reach of the pipes. [SHOW PICTURE]. This picture demonstrates what the pipe system will look like after the minga is finished. The river is drawn in blue, the pipes in red, and the houses in black. So, only half of the community will receive running water as the result of this minga. That is, only half of the community will benefit directly as the result of this minga.

A lot of hard work is involved in this minga, so the minga will last 2 days. In order to complete this minga in 2 days, the help of all socios in the community is needed. Imagine that only the first day of the minga has been completed. The first day of the minga lasted $9 \mathrm{~h}$. Some of the citizens (socios) in the community worked all day in this minga, but other citizens worked for fewer hours.

I am going to show you pictures of citizens who participated in the first day of the minga, along with two pieces of information about each of these people: (1) whether or not they will receive improved access to water as the result of this minga, that is, how much they will benefit as the result of the minga, and (2) how much they have sacrificed in the minga, that is, how many hours they worked in the first day of the minga.

The pail of water in each picture represents the extent to which each person will benefit as the result of the minga. [SHOW PICTURE]. For example, this person lives close to the river, in reach of the pipe system that will be constructed in the minga. So, he will receive a lot of running water as the result of the minga. That is why there is a picture of a full pail of water here. This full pail of water represents that this man will benefit a lot as a result of this minga. [SHOW PICTURE]. This person, however, will not benefit much from the minga, because he lives far from the river, too far for the pipes to reach. That is why there is a picture of an almost-empty pail of water here. This almost-empty pail of water represents that this man will not benefit much as a result of this minga.

The circle in each picture represents how many hours each person has worked in the minga so far. [SHOW PICTURE]. For example, this person worked for the entire first day of the minga-he worked for nine hours. That is why $3 / 4$ of the circle is filled in, and why there is a number " 9 " drawn next to the circle; this represents that the person worked for $9 \mathrm{~h}$ in the minga. [SHOW PICTURE]. This person, however, has worked for only $3 \mathrm{~h}$ in the minga so far. That is why only $1 / 4$ of the circle is filled in, and why there is a number " 3 " drawn next to the circle; this represents that the person has worked for only $3 \mathrm{~h}$ in the minga. [MAKE SURE SYMBOL MEANINGS ARE UNDERSTOOD].

Now, I am going to show you pictures of 2 of the minga participants, and tell you how much they will benefit as the result of the minga, and how long they have worked in the minga so far. Then I will ask you:

1. Which one of the people deserves more respect, based on his participation in the minga?

2. If you were the leader of this community, and you could decide whether citizens should be punished based on their participation in the minga, which of these people would you think should be punished?

\section{References}

Aguirre, T. A. (1952). Minga y su funcion social. Tlatoani, 1, 17-18.

Albanese, R., \& Van Fleet, D. D. (1985). Rational behavior in groups: The free-riding tendency. Academy of Management Review, 10, 244-255.

Alexander, R. D. (1979). Darwinism and human affairs. Seattle: University of Washington Press.

Andreoni, J., Harbaugh, W., \& Vesterlund, L. (2003). The carrot or the stick: Rewards, punishments and cooperation. American Economic Review, 93, 893-902.

Axelrod, R., \& Hamilton, W. D. (1981). The evolution of cooperation. Science, 211, 1390-1396.

Bornstein, G., \& Ben-Yossef, M. (1994). Cooperation in intergroup and single-group social dilemmas. Journal of Experimental Social Psychology, 30, 52-67.

Bottom, W. P., Gibson, K., Daniels, S. E., \& Murnighan, J. K. (2002). When talk is not cheap: Substantive penance and expressions of intent in rebuilding cooperation. Organization Science, 13, 497-513. 
Boyd, R., Gintis, H., Bowles, S., \& Richerson, P. J. (2003). The evolution of altruistic punishment. Proceedings of the National Academy of Sciences (USA), 100, 3531-3535.

Boyd, R., \& Richerson, P. J. (1988). The evolution of reciprocity in sizable groups. Journal of Theoretical Biology, 132, 337-356.

Buss, D. M., \& Schmidt, D. P. (1993). Sexual strategies theory: An evolutionary perspective on human mating. Psychological Review, 100, 204-232.

Chagnon, N. A. (1988). Life histories, blood revenge, and warfare in a tribal population. Science, 239, 985-992.

Chagnon, N. A. (1997). Yanomamö. Fort Worth: Harcourt Brace.

Chagnon, N. A., \& Bryant, J. R. (1984). Kindemcom: the fourth style in the study of human kinship relationships. New York: Harry Guggenheim Foundation.

Cosmides, L. (1989). The logic of social exchange: Has natural selection shaped how humans reason? Studies with the Wason selection task. Cognition, 31, 187-276.

Cosmides, L., \& Tooby, J. (1989). Evolutionary psychology and the generation of culture, Part II. Case study: A computational theory of social exchange. Ethology and Sociobiology, 10, 51-97.

Cosmides, L., \& Tooby, J. (1992). Cognitive adaptations for social exchange. In J. H. Barkow, L. Cosmides, \& J. Tooby (Eds.), The adapted mind: Evolutionary psychology and the generation of culture (pp. 163-228). New York: Oxford University Press.

Dawkins, R. (1976). The selfish gene. Oxford: Oxford University Press.

Delton, A. W. (2005). What counts as free riding? Using intentionsbut not contribution level- to identify free riders. Paper presented at the 17th meeting of the Human Behavior and Evolution Society, Austin, Texas.

Dufwenberg, M., \& Kirchsteiger, G. (1999). A theory of sequential reciprocity. Discussion paper, CentER, Tilburg University.

Eckel, C. E., \& Grossman, P. J. (1996). The relative price of fairness: Gender differences in a punishment game. Journal of Economic Behavior and Organisation, 30, 143-158.

Ehrhart, K., \& Keser, C. (1999). Mobility and cooperation: on the run. Working Paper 99s- 24, CIRANO, Montreal.

Erasmus, C. J. (1977). In search of the common good. New York: The Free Press.

Falk, A., Fehr, E., \& Fischbacher, U. (2005). Driving forces behind informal sanctions. Econometrica, 73, 2017-2030.

Fehr, E., \& Gächter, S. (2000). Cooperation and punishment in public goods experiments. American Economic Review, 90, 980-994.

Fehr, E., \& Gächter, S. (2002). Altruistic punishment in humans. Nature, 415, 137-140.

Fehr, E., \& Schmidt, K. M. (1999). A theory of fairness, competition, and cooperation. The Quarterly Journal of Economics, 114, 817-868.

Fiddick, L., \& Cummins, D. D. Are perceptions of fairness relationship specific? The case of noblesse oblige. Quarterly Journal of Experimental Psychology (in press).

Fiddick, L., Spampinato, M. V., \& Grafman, J. (2005). Social contracts and precautions activate different neurological systems: An fMRI investigation of deontic reasoning. NeuroImage, 28, 778-786.

Goren, H., Kurzban, R., \& Rapoport, A. (2003). Social loafing vs. social enhancement: Public goods provisioning in real-time with irrevocable commitments. Organizational Behavior and Human Decision Processes, 90, 277-290.

Hagen, E. H. (2003). Kinsanity genealogy analysis software. Retrieved July 24, 2003 from http://itb.biologie.hu-berlin.de/ hagen/kinsanity/.

Hagen, E. H., Barrett, H. C., \& Price, M. E. (2006). Do human parents face a quantity-quality tradeoff? Evidence from a Shuar community. American Journal of Physical Anthropology, 130, 405-418.

Hamilton, W. D. (1964). The genetical evolution of social behaviour, I and II. Journal of Theoretical Biology, 7, 1-52.

Harner, M. J. (1972). The Jivaro: people of the sacred waterfalls. Garden City, NY: Anchor.

Hawkes, K. (1993). Why hunter-gatherers work - an ancient version of the problem of public goods. Current Anthropology, 34, 341-361.
Henrich, J., Boyd, R., Bowles, S., Camerer, C., Fehr, E., \& Gintis, H. (2004). Foundations of human sociality. Oxford: Oxford University Press.

Henrich, J., Boyd, R., Bowles, S., Camerer, C., Fehr, E., Gintis, H., et al. (2001). In search of Homo economicus: Experiments in 15 smallscale societies. American Economic Review, 91, 73-78.

Masclet, D., Noussair, C., Tucker, S., \& Villeval, M. (2003). Monetary and nonmonetary punishment in the voluntary contributions mechanism. American Economic Review, 93, 366-380.

Olson, M. (1965). The logic of collective action: Public goods and the theory of groups. Cambridge: Harvard University Press.

Ostrom, E. (1990). Governing the commons: The evolution of institutions for collective action. New York: Cambridge University Press.

Ostrom, E., Walker, J., \& Gardner, R. (1992). Covenants with and without a sword - self governance is possible. American Political Science Review, 86, 404-417.

Page, T., Putterman, L., \& Unel, B. (2005). Voluntary association in public goods experiments: reciprocity, mimicry and efficiency. The Economic Journal, 115, 1032-1053.

Patton, J. Q. (2000). Reciprocal altruism and warfare: A case from the Ecuadorian Amazon. In L. Cronk, N. A. Chagnon, \& W. Irons (Eds.), Adaptation and human behavior: An anthropological perspective (pp. 417-436). New York: Aldine de Gruyter.

Patton, J. Q. (2005). Meat sharing for coalitional support. Evolution and Human Behavior, 26, 137-157.

Price, M. E. (2003). Pro-community altruism and social status in a Shuar village. Human Nature, 14, 191-208.

Price, M. E. (2005). Punitive sentiment among the Shuar and in industrialized societies: Cross- cultural similarities. Evolution and Human Behavior, 26, 279-287.

Price, M. E. (2006). Monitoring, reputation and greenbeard reciprocity in a Shuar work team. Journal of Organizational Behavior, 27, 201-219.

Price, M. E., Cosmides, L., \& Tooby, J. (2002). Punitive sentiment as an anti-free rider psychological device. Evolution and Human Behavior, 23, 203-231.

Rabin, M. (1993). Incorporating fairness into game theory and economics. American Economic Review, 83, 1282-1302.

Sefton, M., Shupp, R., Walker, J. (Under review). The effect of rewards and sanctions in provision of public goods. Economic Inquiry.

Shinada, M., Yamagishi, T., \& Ohmura, Y. (2004). False friends are worse than bitter enemies: Altruistic punishment of in-group members. Evolution and Human Behavior, 25, 379-393.

Singer, T., Kiebel, S. J., Winston, J. S., Dolan, R. J., \& Frith, C. D. (2004). Brain responses to the acquired moral status of faces. Neuron, 41, 653-662.

Singer, T., Seymour, B., O’Doherty, J. P., Stephan, K. E., Dolan, R. J., \& Frith, C. D. (2006). Empathic neural responses are modulated by the perceived fairness of others. Nature, 439, 466-469.

Steel, D. (1999). Trade goods and Jívaro warfare: The Shuar 18501957, and the Achuar 1940- 1978. Ethnohistory, 46, 745-776.

Stone, V. E., Cosmides, L., Tooby, J., Kroll, N., \& Knight, R. T. (2002). Selective impairment of reasoning about social exchange in a patient with bilateral limbic system damage. Proceedings of the National Academy of Sciences USA, 99, 11531-11536.

Sugiyama, L., Tooby, J., \& Cosmides, L. (2002). Cross-cultural evidence of cognitive adaptations for social exchange among the Shiwiar of Ecuadorian Amazonia. Proceedings of the National Academy of Sciences USA, 99, 11537-11542.

Tooby, J., Cosmides, L., \& Price, M. E. (2006). Cognitive adaptations for n-person exchange: The evolutionary roots of organizational behavior. Managerial and Decision Economics, 27, 103-129.

Trivers, R. (1971). The evolution of reciprocal altruism. Quarterly Review of Biology, 46, 35-57.

Yamagishi, T. (1986). The provision of a sanctioning system as a public good. Journal of Personality and Social Psychology, 51, $110-116$. 